\title{
Atos de fala performáticos e a produção de identidades fragmentadas
}

\section{Performatic speech acts and the production of fragmented identities}

DOI: 10.46814/lajdv3n1-018

Recebimento dos originais: 30/10/2020

Aceitação para publicação: 23/12/2020

Naiara de Paiva Vieira

Mestre em Letras pela UFOP; Professora particular de Português e Redação

Instituição: Universidade Federal de Ouro Preto (UFOP)

Endereço: Rua José Elias Filho, $\mathrm{n}^{\circ}$ 72, Centro. Bom Sucesso (MG)

E-mail: naiarav@yahoo.com.br

\section{RESUMO}

Este artigo é o início de uma pesquisa desenvolvida na linha 2: Tradução e Práticas Discursivas, do Programa de Pós-Graduação em Letras: Estudos da Linguagem, da Universidade Federal de Ouro Preto (UFOP). Depois de discutir sobre a questão da fragmentação identitária, se enfocará em como a linguagem performática produz efei- tos na sociedade e nos sujeitos. Primeiramente, a discussão partirá da relação entre cultura e identidade, segundo a visão de cultura de Vivan (2011), e a perspectiva teórica de identidade de Hall (2005) e Bauman (2005). Posteriormente, se enfocará nos es- tudos pragmáticos de Austin, citado por Ottoni (1998). Para tratar da produção desses atos de fala, as contribuições de Muniz (2010), sobre as formas de exclusão que estão presentes na linguagem e a discussão de Rajagopalan (2000), sobre a linguagem politi- camente correta, serão discutidas. Por fim, se enfocará nos estudos de Pinto (2007) so- bre como os atos de fala fazem o corpo por meio da linguagem performativa.

Palavras-chave: Performatividade, Atos de fala, Identidade.

\begin{abstract}
This article is the beginning of a research developed in line 2: Translation and Discursive Practices, of the Graduate Program in Languages: Language Studies, of the Federal University of Ouro Preto (UFOP). After discussing the issue of identity fragmentation, it will focus on how performative language produces effects on society and subjects. First, the discussion will start from the relationship between culture and identity, according to Vivan's (2011) vision of culture, and Hall's (2005) and Bauman's (2005) theological perspective of identity. Later, it will focus on the all-round pragmatics of Austin, quoted by Ottoni (1998). To deal with the production of these speech acts, the contributions of Muniz (2010), on the forms of exclusion that are present in language and the discussion of Rajagopalan (2000), on politically correct language, will be discussed. Finally, the focus will be on Pinto's (2007) studies on how speech acts make the body through performative language.
\end{abstract}

Keywords: Performativity, Acts of Speech, Identity.

\section{INTRODUÇÃO}

O instrumento principal das interações sociais e de que decorre todo o desenvolvimento humano é a linguagem. É na e através da linguagem que representações sociais são desenvolvidas e 
transformadas. Nessa perspectiva, apoiando na visão pragmática de estudo do uso linguístico, ou seja, da linguagem em uso, ou mesmo da prática linguística que, segundo Levinson (1983), produz sentido a partir das palavras e para além delas, dependendo do contexto de uso, podemos entender como a linguagem é usada nas representações sociais e como os atos de nomear alguém, ou se autonomear, produzem sentidos na sociedade. Para tanto, se enfocará no estudo particular do filósofo da linguagem John Austin, inaugurador da pragmática através de sua teoria de atos de fala.

Os estudos pragmáticos de Austin, citado por Ottoni (1998), nos diz que a linguagem é performática, ou seja, ao proferir um enunciado estamos praticando uma ação. O sujeito assume seu papel de agente através de seu discurso, transformando a realidade da qual faz parte e a sua própria realidade individual. Sendo assim, ao analisarmos os atos de fala, além de se entender os efeitos de tais atos para a sociedade, se entenderá também os efeitos desses atos para o sujeito, buscando clarear como a visão performativa da linguagem ajuda na compreensão da fragmentação da identidade do sujeito.

Partindo desse princípio, se discorrerá sobre os estudos identitários de Hall (2005) e Baumam (2005) e suas explicações sobre fragmentação identitária e os estudos de linguagem e exclusão de Rajagopalan (2010), Muniz (2010) e Ferreira (2010) para tratar da questão dos atos de fala e de como ao pronunciar um enunciado performático estamos praticando uma ação social. Também serão discutidos os estudos de Pinto (2007), em que a autora levanta questionamentos sobre se a linguagem, sendo performática, faz o corpo.

A fundamentação teórica será dividida em quatro partes. Na primeira parte que é a "Problemática da identidade no campo da cultura", se estabelecerá uma relação entre cultura, segundo a visão de Vivan (2011), e a fragmentação identitária, com base em Hall (2005) e Bauman (2005). Na segunda parte, "Linguagem e performatividade", se enfocará nos estudos pragmáticos de Austin, citado por Ottoni (1998) e em sua teoria de atos de fala. Já na terceira parte "O ato de nomear no processo de identificação", se enfocará na produção desses atos de fala, levando em conta as contribuições de Muniz (2010), sobre as formas de exclusão que estão presentes na linguagem e a discussão de Rajagopalan (2000), sobre a linguagem politicamente correta. Na quarta, e última parte, “Corpo e performatividade", se aterá nos estudos de Pinto (2007), em que a autora faz uma discussão sobre como os atos de fala, por meio da linguagem, fazem o corpo.

\section{FUNDAMENTAÇÃO TEÓRICA}

\subsection{PROBLEMÁTICA DA IDENTIDADE NO CAMPO DA CULTURA}

Segundo Ferreira (2010), é no século XX que começam a repercutir os problemas de identidade com a fragmentação das relações humanas, declínio de velhas identidades e surgimento de novas formas de identificação. Segundo Hall, a questão da identidade tem sido amplamente problematizada 
em várias áreas. Estamos passando atualmente por uma "crise de identidade", a identidade somente se constitui em proble- ma quando está em crise. Nas palavras dele, "velhas identidades, que por tanto tempo estabilizaram o mundo social, estão em declínio, fazendo surgir novas identidades e fragmentando o indivíduo moderno, até aqui visto como um sujeito unificado" (HALL, 2005, p. 7). Essa "crise de identidade" refere-se a uma descentralização dos indivíduos tanto do seu lugar no mundo social e cultural, quanto de si mesmos. (Idem, ibidem, p. 9)

Hall (2005) faz um grande percurso teórico identitário até chegar à concepção defendida por ele de sujeito pós-moderno. As três concepções identitárias abordadas por Hall (2005) relacionam-se a três concepções de sujeitos: o sujeito do iluminismo, o sujeito sociológico e o sujeito pós-moderno. Na concepção de sujeito do iluminismo, Hall explica que o núcleo ou o centro essencial do eu é a identidade de uma pessoa. Sendo assim, o sujeito nasce com uma identidade fixa que se desenvolve ao longo de sua existência, no entanto, ele permanece essencialmente o mesmo. Essa é, critica o autor, uma concepção muito individualista do eu e de sua existência, que salienta a permanência de uma mesma e imutável configuração identitária.

Já a concepção do sujeito sociológico é vista como uma concepção "interativa" da identidade do eu, em que o sujeito ainda continua tendo um núcleo ou uma essência identitária interior que é chamada de "eu real", mas esta é formada e modificada na "interação" entre o eu e a sociedade.

Por fim, a concepção de identidade defendida por Hall (2005) é a concepção de sujeito pósmoderno, em que o sujeito é visto como não tendo uma identidade fixa ou essencial. A identidade torna-se uma "celebração móvel”, em que é formada e transformada continuamente com a manutenção de contato com as diversas culturas que nos rodeiam. Vista dessa maneira, essa concepção de identidade é definida contextual e historicamente e não biologicamente. O sujeito lida com vários traços que preexistem nele e que, ao mesmo tempo, são incoerentes. Hall, apoiando- se em Lacau (1990) aponta que:

\footnotetext{
As sociedades da modernidade tardia, são caracterizadas pela "diferença"; elas são atravessadas por diferentes divisões e antagonismos sociais que produzem uma variedade de diferentes "posições de sujeito" - isto é, identidades - para os indivíduos". Se tais sociedades não se desintegram totalmente não é porque elas são unificadas, mas porque seus diferentes elementos e identidades podem, sob certas circunstâncias, ser conjuntamente articulados. Mas essa articulação é sempre parcial: a estrutura da identidade permanece aberta. (HALL, 2005, p. 17)
}

Quando se entra em contato com "outra" cultura, se entra em contato com vários tipos de diferenças e isso acarreta várias transformações de identidade. Percebo assim, que o conceito pósmoderno de identidade, sugerido por Hall, está intimamente ligado ao conceito de cultura. Para explicar 
melhor essa relação, cito aqui uma definição de cultura apontada por Kramsch que me parece apropriada para esta investigação:

[...] cultura pode ser definida como membro em uma comunidade discursiva que partilha um espaço social e história comuns, e "imaginings" comuns. Mesmo quando eles deixaram aquela comunidade, seus membros podem conservar, onde eles estiverem, um sistema comum de padrões de percepção, crença, avaliação e atitudes. Estes padrões são geralmente chamados de sua "cultura". (1998 apud VIVAN, 2011, p. 4)

O conceito de cultura é entendido como um conceito plural, em que não existe uma cultura "pura", mas sim, uma miscigenação de culturas. Sendo assim, mesmo que os sujeitos mudem de contexto cultural, mudando assim também de cultura, eles conservarão certos padrões identitários de sua cultura, assim como "herdarão" outros padrões culturais identitários. Hall (2005) afirma que o mesmo ocorre com a identidade nacional em que o indivíduo se forma e se transforma no interior do sistema de representação cultural. Portanto, é errôneo pensar a cultura nacional como expressão da cultura subjacente de "um único povo" porque as nações modernas são todas "híbridos culturais".

Pensando nesse conceito plural de cultura e nas transformações identitárias que são ocasionadas por essa pluralidade cultural, fica claro que a identidade é inventada e não descoberta. Bauman (2005) diz que o indivíduo inventa sua própria identidade ao se relacionar com os participantes não homogêneos de um grupo cultural. Segundo Bauman (2005), a ideia de "identidade" nasceu da crise do pertencimento, ou seja, da recriação da identidade à semelhança da ideia do indivíduo. O indivíduo cria e recria sua identidade de acordo com seus "objetivos" pessoais e sociais quando inserido em um grupo.

\subsection{LINGUAGEM E PERFORMATIVIDADE}

Segundo Levinson (1983), a pragmática deu um grande salto quando trabalhos de Austin, Strawson, Grice e Searle em particular combateram ativamente a ideia de Chomsky, Bloofieldian de gramática gerativa. Trabalhos como de Austin e dos outros linguistas pretendem mostrar a importância dos usos da língua para entendermos sua natureza. Para o filósofo, a linguagem e o sujeito não têm uma função descritiva, mas uma função de agência sobre a sociedade e sobre os sujeitos. De acordo com Ottoni (1998), Austin é um "desconstrutor” da filosofia tradicional e da linguística tradicional na medida em que rompe com a fronteira entre filosofia e linguística e implanta algo novo, a visão performativa da linguagem.

Ao romper com a fronteira entre o linguístico e o filosófico, a performatividade adquire um estatuto único nos estudos da linguagem e Austin continua a entregá-la para denominar toda "fala" humana, cai as- sim por terra a separação entre sujeito e objeto. A visão que o sujeito vai ter de um 
objeto para caracterizá-lo, classificá-lo ou mesmo nomeá-lo vai depender não só do conhecimento que o sujeito tem do objeto, mas tam- bém da maneira como ele o percebe em determinado contexto. $\mathrm{O}$ contexto é então fundamental para a linguagem performativa, porque dependendo do contexto em que o sujeito se encontra ele se identificará estrategicamente.

Sendo assim, Austin diz ser o performativo ao mesmo tempo ação e enunciado, a própria falaação, independente da forma linguística (forma estrutural), nas palavras dele "Além disso, é preciso acrescentar que nosso performativo é ao mesmo tempo ação e enunciado" (OTTONI, 1998, p. 113). O enunciado é a forma linguística (frase) que tem embuti- da uma ideia de ação (agir por meio da frase). Para explicar essa ação do performativo, Austin diz ser preciso ter a "situação total de fala" para se perceber essa agência total do sujeito. $\mathrm{O}$ autor diz que os atos de fala são compostos de três atos simultâneas: locucionário, ilocucionário e perlocucionário. $\mathrm{O}$ ato locucionário é o próprio enunciado, o ilocucionário é a realização de uma ação através do enunciado, é a força que o enunciado vai ter, podendo ser de crítica, ironia, preconceito, etc. e o ato perlocucionário são os efeitos que os atos de fala produziram no interlocutor. Esses atos de fala propostos por Austin rompem com significado dos enuncia- dos, ou seja, não há mais lugar para fazer uma distinção entre sentido e significado das palavras quando se trata de performatividade.

Por trás de cada afirmação há assim um performativo mascarado embutido no enunciado performativo, que sempre será na primeira pessoa do singular e do verbo no presente do indicativo. Por exemplo, quando digo que "ele é uma boa pessoa", esse enunciado pode ser interpreta- do de várias maneiras dependendo do lugar em que estou. O enunciado pode ter o sentido de "eu afirmo que ele é uma boa pessoa", ou "eu imagino que ele é uma boa pessoa". Nesse ponto, Austin nos diz que o enunciado é identificado com o sujeito falante para se poder praticar a ação. A afirmação constativa de que "ele é uma boa pessoa” está no nível do per- formativo. As afirmações passam a não somente dizer algo no mundo, como também a fazer algo no mundo. Austin, citado por Ottoni então conclui “"[...] não existe nenhum critério verbal para distinguir o enuncia- do performativo do enunciado constativo, e que o constativo está sujeito às mesmas infelicidades que o performativo" (OTTONI, 1998, p. 119). Com esse caráter não verbal do performativo, Austin soube ao mesmo tempo discutir a linguagem humana e o humano. Como ninguém, mostrou que a linguagem não se distancia do humano, do seu corpo e mostrou como linguagem e corpo se fundem.

\subsection{O ATO DE NOMEAR NO PROCESSO DE IDENTIFICAÇÃO}

Os atos de fala, como nos aponta Muniz, podem ser entendidos como um contrato, "Os atos de fala consistem exatamente nisso: num contrato ou compromisso entre as partes de realizarem a ação que fica subjacente à fala" (MUNIZ, 2009, p. 36). Sendo assim, tudo na teoria da performatividade 
pode ser revisto, não existe verdadeiro ou falso. O ato performativo de se autonomear "mulher", “negro", "gay” etc., não pode ser constatado como verdadeiro ou falso porque exprime um desejo, não uma verdade. $\mathrm{O}$ que se pretende mostrar é que a nomeação é muito mais política e estratégica, e às vezes de identificação, do que a constatação de uma verdade.

Nos auto identificarmos com nossas identidades, é uma estratégia política na medida em que demonstramos o orgulho de ser quem somos e reivindicamos nossos direitos. O essencialismo estratégico por parte dos negros, por exemplo, é uma estratégia de luta, é na luta que os negros se auto afirmam, ressaltando a diferença para poderem agir politicamente na sociedade. No entanto, encarando a identidade de forma una, fixa e imutável, alguns problemas são decorrentes, um exemplo seria os movimen- tos feministas citados no artigo, por exemplo, quando falamos de feminismo, de qual feminismo estamos falando já que por mulher entende-se: "branca, classe média, heterossexual, religiosa, mãe, etc. Esse conflito é estabelecido porque o ser humano sempre está em busca de sua essência, sem perceber que somos no outro, é por eu saber quem eu não sou, que eu me defino, me defino assim através da diferença que é o outro. Os movimentos raciais, feministas etc., são importantes socialmente, no entanto devemos pensar esses movimentos como um deslocamento do fixo, como relacional para que não fiquemos presos apenas a eles.

Quando nomeamos alguém de "estrangeiro/a", "negro/a", "branco/a", "mulher", "homem", "gay" etc., estamos enquadrando as pessoas em estereótipos e as colocando em identidades fixas, congeladas, o que não existe. Muniz nos diz que "A perspectiva dos "novos" estudos pragmáticos, segundo Rajagopalan (2006) está calcada nas políticas de linguagem e também na política da própria linguística como ciência" (MU- NIZ, 2010, p. 101). Ou seja, esse ato performativo político de nomear o Outro nunca vai ser neutro e por isso transforma a diferença em desigualdade. Na necessidade que temos de nomear o mundo e as pessoas, está pressuposta a noção de classificação que é tão cara ao pensamento eurocêntrico ocidental. Muniz nos diz:

Classificar tanto como adicionar é um reflexo de nosso pensamento cartesiano, é parte integrante de nossa maneira de observar o mundo... Classificar é substituir a diversidade infinita do real por um número limitado de categorias. Se trata de um meio sumamente poderoso, não somente para compreender, mas também para submeter ou transformar a realidade. No entanto, é uma técnica totalmente subjetiva, que depende do indivíduo, que estabelece as regras do jogo e do meio sociocultural no qual se desenvolve este sujeito. (MUNIZ, 2010, p. 104)

O que acontece é que o poder que a linguagem tem de nomear ao mesmo tempo confere uma existência e a ameaça. Quando usamos nomes como "estrangeiro", "negro", "mulher", "homossexual”, entre outros, ou seja, nomes que sofreram uma naturalização ao longo da história, somos eficazes em descriminar, excluir, porque tais nomes passam a ferir as pessoas que os recebem, a história do nome 
passa a ser interna ao no- me. Muniz (2010) nos diz que a identidade, segundo Rajagopalan, se constrói na língua e através dela, isso ocorre por a língua estar em constante mudança e evolução, assim como nos aponta Bakhtin (1995). A identidade se encontra assim em um fluxo constante em que, juntamente com a língua, está em constante mudança, por isso é tão complexo falar em identidade e não em identidades, ou ainda identificação, como nos sugere Hall (2005). Sabendo dessa não essencialidade da identidade, o que os movimentos sociais têm proposto é um deslocamento da visão essencialista de alguns termos, por exemplo, o feminismo. Só através da busca de rompimento desses nomes "essenciais", que assolam a sociedade, conseguiremos uma sociedade mais igualitária e menos preconceituosa.

Rajagopalan, nos fala da linguagem "politicamente correta" como forma de amenizar preconceitos, "A linguagem "politicamente correta" tem sido alvo de críticas acirradas advindas de todos os lados. Tanto isso é verdade que hoje em dia é difícil encontrar alguém que abertamente se disponha a discuti-la se não em tom de desprezo e desconfiança” (RAJAGOPALAN, 2000, p. 1). Tratar da linguagem "politicamente correta" hoje em dia é encarado por muitos como modismo. Alguns intelectuais, ditos de esquerda, acreditam que a linguagem "politicamente correta" é uma alternativa dos intelectuais, ditos de direita, de tapar o sol com a peneira, ou seja, para esses intelectuais o problema não está na linguagem, mas nas pessoas que fazem uso dela. O que tem ocorrido com essa grande contradição de pensamento entre os intelectuais de esquerda e de direita é que se está tornando cada vez mais politicamente correto falar com desprezo sobre a linguagem "politicamente correta", sem, no entanto, procurar uma solução para o dilema. Embora os intelectuais digam que é justamente o preconceito que gera tais efeitos de sentido sobre a linguagem, Possenti (1995) citado por Rajagopalan (2000), um dos linguistas que se contrapõe a linguagem "politicamente correta", nos diz que não podemos negar que o discurso preconceituoso realimenta as condições sociais que dão suporte às ideologias e aos próprios discursos.

Alguns questionamentos sobre a linguagem "politicamente correta" são: "o que adianta efetuar mudanças na linguagem, já que isso não vai ter nenhuma influência sobre o pensamento? O que adianta trocar a roupagem se a pessoa por trás permanece a mesma?” (RAJAGOPALAN, 2000, p. 3). Argumenta-se que os que defendem a linguagem "politica- mente correta" estão querendo camuflar a realidade, não confrontando o verdadeiro problema. No entanto, se pensarmos na natureza agente do sujeito e, portanto, da linguagem da qual o sujeito faz uso, a linguagem tem sim um poder transformador. O que devemos entender é que a linguagem descreve e performa o mundo, e é através do caráter performativo da fala-ação que o sujeito pode transformar o mundo. Sendo assim, para começar essa transformação, é preciso o uso da linguagem "politicamente correta" como forma de luta contra os preconceitos. Rajagopalan (2000) conclui então dizendo que é importante sim o esforço de 
se usar a linguagem "politicamente correta" como forma de amenizar os preconceitos, já que saná-los é complicado, a luta contra os preconceitos tem que ser persistente e incansável. Os preconceitos são produzidos e mantidos por meio da linguagem, por isso é tão importante seu monitoramento, e ao monitorar sua própria fala, o usuário precisa se conscientizar da existência dos preconceitos impressos em sua linguagem.

\subsection{CORPO E PERFORMATIVIDADE}

Outra forma de enquadramento e preconceito é a relação entre linguagem e corpo. Partindo da ideia de Austin de que linguagem e corpo se fundem, Pinto (2007) nos questiona se a "linguagem faz o corpo" e sobre "o que é feminino e o que é masculino". Para se responder a essas questões, usamos as representações de gêneros. É por isso que segundo Pinto (2007), usamos expressões como: 1) "Fale como homem rapaz!" e 2) "As mulheres falam mais que os homens" (p. 3). Pinto nos diz que "Esse tipo de enunciado relaciona determinada prosódia a uma representação de um conjunto de corpos masculinos, e determinado tipo de retórica a uma representação do conjunto de corpos femininos" (PINTO, 2007, p. 3). Essa visão entende o corpo como um conjunto de papéis sexuais, em uma sociedade que é um sistema de divisão de trabalho. Pinto (2007), citando Butler, nos diz que gênero é, portanto, um efeito de atos de fala que apresenta uma estrutura sempre binária e hierarquizada. A teoria de gênero proposta por Butler, e discutida por Pinto (2007), problematiza a visão feminista de gênero, que gira em torno do "sexual" apenas.

Segundo Pinto (2007), o termo usado por Butler (1999) para definir gênero é stylization, que é uma nominalização do verbo stylize, cujo melhor significado seria fazer conformar a um dado estilo ou tornar convencional. Sendo assim, essa questão de gênero é bem mais vista em nossa sociedade como convenção de práticas e comportamentos sociais. Pinto propõe esse esforço de separar gênero de anatomia para não se cair em uma naturalização do gênero, ou seja, atribuir determinadas características chamadas femininas somente às mulheres e determinadas características chamadas masculinas somente aos homens. Nas palavras dela:

\footnotetext{
A teoria de gênero problematiza essa ideia de uma organização simples em torno do "sexual". Ainda que a anatomia seja um componente importante a ser analisado, deve-se levar em consideração antes de qualquer coisa que o gênero é uma estilização do corpo. Não a anatomia, mas os atos de fala que se organizam em torno desta. (PINTO, 2007, p. 3)
}

Pinto, citando Butler, nos fala da questão da agência do sujeito na e através da linguagem e conclui que "O sujeito de fala é aquele que produz um ato corporalmente; o ato de fala exige o corpo. $\mathrm{O}$ agir no ato de fala é o agir do corpo, e definir esse agir é justamente discutir a relação entre linguagem e corpo" (PINTO, 2007, p. 11). Aqui percebemos a relação dialética entre enunciado e corpo. Ou seja, 
o que faz do ato de fala uma ação é a força da ilocução e do movimento do agir do corpo que executa a ilocução. É interessante pensarmos que o efeito do ato de fala é operado ao mesmo tempo pelo que é dito, pelo quem diz e pelo como é dito (como o corpo diz, como o enunciado diz). Assim a ação do sujeito não está somente no seu enunciado, mas também no corpo que fala e pra- tica uma ação em um determinado contexto. Assim sendo, entendemos a performatividade não como uma capacidade de ação efetuada pelo enunciado, mas sim como uma capacidade de ação, tanto sonora quanto corporal, operada pelo ato de fala.

A partir dessa visão intrínseca estabelecida entre linguagem e corpo, surgem os problemas de identidade. Pinto nos diz que:

A partir deste ponto, o debate sobre o ato de fala como um ato corporal leva aos problemas da identidade. Em que termos a identidade de falante deve ser tratada tendo em vista que o corpo tanto quanto a linguagem são inseparavelmente partes do ato de fala? Em que medida a identidade linguística pode ser estrategicamente separada da identidade corporal para uma análise linguística...? (PINTO, 2007, p. 13)

Esses questionamentos nos trazem outros, por exemplo: o que são identidades, se identidades, não podem ser "encontradas" na linguagem, se não são o que define o sujeito por antecipação? Perguntas como essas nos faz perceber que a linguagem não expõe as identidades dos sujeitos, mas sim que elas são construídas pelos atos de fala. Pinto nos dá uma definição de identidade dizendo que do ponto de vista dos atos de fala, identidade são performativas, ou seja, são efeitos dos atos que impulsionam marcações em quadros de comportamentos. Nas palavras dela:

Do ponto de vista dos atos de fala, identidades são performativas, ou seja, são efeitos de atos
que impulsionam marcações em quadros de comportamentos (fala, escrita, vestimentas,
alimentação, cultos, elos parentais, filiações, etc.). Identidades são construções exigidas pelos
ritos convencionais que postulam o sujeito de maneira a garantir a possibilidade de "nós" a
partir da significação da existência prévia do "eu". (PINTO, 2007, p. 16)

Sendo assim, as identidades não preexistem à linguagem. As identidades precisam ser assim marcadas pelos falantes nos atos de fala continuamente para que o "eu" e o "nós" possam ser sustentados. Segundo a teoria dos atos de fala, as identidades não existem fora desse ato, por isso a repetição é necessária. Pinto então nos diz que:

Isso desloca o próprio conceito de identidade linguística. Se assumirmos a performatividade como o que obriga o sujeito a se constituir em processo, a identidade de falante é também performativa, ou seja, não existe senão na prática e na história de sua própria exibição - e é por isso mesmo sempre múltipla, fragmentada e repetível. (PINTO, 2007, p. 16)

Identidades não são postuladas somente na língua, elas são criadas por marcações do corpo que significa o sujeito previamente e são produzidas assim pelos atos de fala que garantem suas existências. 
Uma marcação de identidade discutida por Pinto (2007) é o gênero. A autora nos diz que as estudiosas feministas procuravam entender como a diferença entre os sexos está articulada entre os diversos atos de nossas vidas e quando ela adquire a aparência de natural e o estatuto de uma hierarquia, era preciso entender para combater as desigualdades sociais. Apesar dessa preocupação das estudiosas feministas em desnaturalizar a hierarquia entre os sexos, elas não discutiram a questão da estilização do corpo. A distinção homem/mulher, segundo a autora, é uma heterossexualidade compulsória, porque é fundamentada no aparelho reprodutor. Pensa-se que o homem que fecunda e a mulher que gera e dá a luz como representações do masculino e do feminino. Esse enquadramento identitário de gênero vem desde quando o sujeito nasce, o primeiro efeito de constituição do sujeito quando nasce é a sua orientação sexual (é menino ou me- nina?). Pinto nos diz que estudiosos como Derrida estão preocupados em afirmar a pluralidade da diferença sexual, desfazendo-se assim esse essencialismo de postular a dupla homem/mulher, mas ele parece desconsiderar como as diferenças sexuais impelem ao corpo. Por isso, a autora trata do performativo radical, nas palavras dela:

Num ato performativo entendido radicalmente, o sujeito instala um efeito de gênero, não como quem apenas o descreve (escreve, inscreve) para o outro, mas ao mesmo tempo e principalmente como quem o interpreta para/no outro e lembra o outro/para o outro/para si: marca e opera sua posição na alteridade, apresentando um efeito que excede a intenção do sujeito. Esse excesso produzido é redobrado pelo corpo que fala: corpo previamente significado, e significado nas suas estilizações de gênero. (PINTO, 2007, p. 22)

Sendo assim, a identidade é construída para/no outro e para/no eu a partir da visão do eu sobre/no outro, isso também vale para as estilizações de gênero através do corpo que fala. Para nós é muito difícil aceitar às vezes essa alteridade do sujeito porque como nos diz Woodwaad (2000), citado por Muniz (2009), o ser humano sempre está em busca de sua essência, sem perceber que somos no Outro, é por saber que eu não sou que eu me identifico como "eu". Em contato com "outra" cultura o sujeito relaciona-se com a Outridade e se reconhece, mas não um reconhecimento fixo, imutável, mas sim um reconhecimento sempre mutável e fragmentado. Por isso mesmo segundo Hall (2005) devemos pensar em identificação e não em identidades, para se pensar em uma ideia de processo e não de produto. Hall nos diz que:

Assim, ao invés de falarmos da identidade como algo concluído, deveríamos falar de identificação, e vê-la como um processo em andamento. A identidade surge, não tanto da plenitude da identidade, já presente dentro de nós enquanto indivíduos, mas da insuficiência da totalidade, que é "preenchida" a partir do que nos é exterior, pelas formas como imaginamos sermos vistos pelos outros. (1997 apud MUNIZ, 2009, p. 41)

Como nos diz Ferreira, o Outro é produto de uma relação de poder. Nas palavras dele "O outro é sempre aquele que, não tendo o que supostamente caracteriza e funda o mesmo, é constituído como 
diferente (FERREIRA, 2010, p. 22). O outro é, assim, produto de uma relação de poder” (p. 22). O diferente é visto em nossa sociedade como o que não é valorizado por não ser igual a tudo, por fugir a "normalidade", o que não deveria ser assim, com essa visão enganosa perdemos muitos benefícios que a convivência com a Outridade nos proporciona. Construtos sociais do estrangeiro, da mulher, do negro, do índio, do homossexual etc., foram e são representados pela ausência, e me fica a pergunta: ausência de que? A partir da busca dessa hierarquia pode-se perceber que a identidade é ao mesmo tempo inclusão, exclusão e reivindicação e que a diferença é o produto da exclusão e da hierarquia. Por isso, nomear se torna algo tão complicado, pois nomeando se exclui. 


\section{REFERÊNCIAS BIBLIOGRÁFICAS}

BAKHTIN, M. Marxismo e filosofia da linguagem. São Paulo: Hucitec, 1995.

BAUMAN, Z. Identidade (entrevista a Benedetto Vecchi/Zygmunt Bauman). Trad.: Carlos Alberto Medeiros. Rio de Janeiro: Jorge Zahar, 2005.

BUTLER, J. Sovereign performatives in the contemporary scene of utterance. Critical Inquiry, vol. 23, n. 2, p. 350-377, 1997.

FREITAS, A. C. (Org.). Linguagem e exclusão. Uberlândia: Edufu, 2010.

HALL, S. A identidade cultural na pós-modernidade. Trad.: Tomaz Tadeu da Silva e Guaracira Lopes Louro. 10. ed. Rio de Janeiro: DP\&A, 2005.

LEVINSON, S. Pragmátics. Cambridge: Cambridge University Press, 1983.

OTTONI, P. R. Visão performativa da linguagem. Campinas: UNI- CAMP, 1998.

PINTO, J. P. Conexões teóricas entre performatividade, corpo e identidades. D.E.L.T.A., p. 1-26, 2007.

RAJAGOPALAN, K. Sobre o porquê de tanto ódio contra a linguagem "politicamente correta". In: LOPES DA SILVA, F. L.; MOURA, H. M.

M. (Orgs.). O direito à fala: a questão do preconceito linguístico. Florianópolis: Insular, 2000, p. 93 102.

SILVA, T. T. A promoção social da identidade e da diferença. In: STUART HALL, Kathryn Woodward. (Orgs.). Identidade e diferença: a perspectiva dos estudos culturais. Petrópolis: Vozes, 2000, p. 73-102.

VIVAN, E. G. S. Língua e cultura: entre a submissão e contestação. Revista Sapere, vol. 3, 2011. 